\title{
A most excellent adventure through time
}

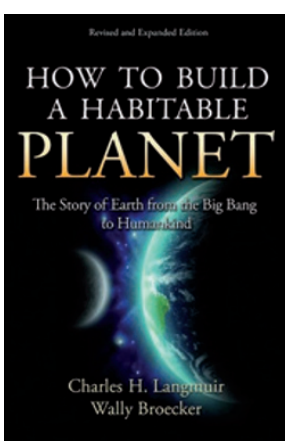

How to Build a

Habitable Planet

by Charles $\mathrm{H}$.

Langmuir and

Wally Broecker

PRINCETON UNIV. PRESS: 2012. 718PP. E27.95

V early three decades ago, Wally Broecker produced a marvellous little book called How to Build a Habitable Planet. The book used new geochemical discoveries, such as those in plate tectonics, to describe how to construct the only habitable planet we know. It spoke to all earth scientists - it was a treasure trove of information for students, and a sparkling source of inspiration for even the most jaded instructor. For me, it was a lifeline during years spent teaching 'rocks for jocks' classes - introductory geology classes seen as the soft science option by large numbers of easily bored students.

Discoveries continue and books age. Now, Charles Langmuir has come together with Broecker to produce a fine second edition. This is a completely different book, wholly updated but also more detailed and more comprehensive. Yet, it keeps the bright flavour of the old version, and remains accessible without compromising on accuracy.

The book begins with an introduction to reductionism, chaos and the characteristics of natural systems. Only after this thoughtful start does the text begin to gallop through time, from the Big Bang, via the synthesis of the raw material, to the heavy construction of the Earth itself. By chapter six, we are on to radioactive dating and the debate about the age of the planet, with nods to the seventeenth century Irish archbishop James Ussher, who calculated that the world was created in $4004 \mathrm{BC}$, and the nineteenth century physicist Lord Kelvin, who argued that the Earth was no more than 40 million years old. The structure and functioning of the Earth and Moon is then explored - the core, mantle and crust are explained, as is plate tectonics.

But why did this particular planet become habitable? Langmuir and Broecker map out the discussion well. Running water is needed, and it must be sustained for
4 billion years or more - an extraordinary requirement. The evolution of the Earth's atmosphere is discussed, as are the complex feedbacks that link atmospheric carbon dioxide concentrations and plate tectonics, and help set the Earth's thermostat. The authors rate our current understanding of the Earth's habitability control system as a six out of ten. They may exaggerate. To borrow the Elizabethan term, this remains terra meta incognita for Earth scientists. We lack consensus on even fundamental issues such as why the air is four-fifths nitrogen and one-fifth oxygen, let alone what controls atmospheric pressure. We're doing better in approaching the great question - asked as early as in the Bible's book of Job - about what controls ocean volume: here, Langmuir and Broecker give a masterly exposition of the interactions between plate tectonics and geochemistry.

Next up is life. Far from struggling against the universal tendency towards disorder, laid down by the laws of thermodynamics, life tends to maximize the rate of change. That is, living organisms create exquisitely ordered arrangements of atoms, ever further from equilibrium, by dissipating thermodynamic gradients. The authors conclude that "given a suitable planetary environment, life can then be viewed with some justification as a natural consequence of planetary evolution". This statement of inevitability, which could be termed 'unintelligent design', has a strong (but perhaps unintended) whiff of the thoughts of evolutionary biologist Richard Dawkins. The theological argument against overt-toall 'intelligent design' is that it removes the necessity of faith that opens eyes. Conversely, the scientific argument against 'unintelligent design' is that it is simply closed-eyes faith,

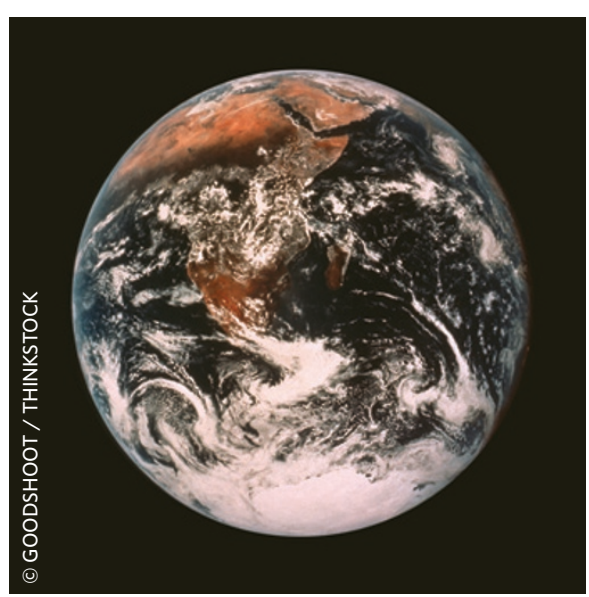

not hard evidence. I'd rather defer to Socrates, the father of the scientific method: we know that we do not know.

A discourse on evolution follows, giving branches to Darwin's tree of life. Ironically, modern molecular phylogeny now busily chops up this tree, which looks increasingly like a braided delta. Then comes a description of the co-evolution of life and the planet. Topics covered include life as an electrical current, the Great Oxidation Event 2.4 billion years ago (when oxygen started to accumulate in the atmosphere), catastrophes, climate and the emergence of human life.

\section{It keeps the bright flavour of the old version, and remains accessible without}

\section{compromising on accuracy.}

Langmuir and Broecker deliver an eloquent and concise guide to the Anthropocene and its perils. "Is there intelligent life on Earth?" asked a chalk scrawl on a wall I used to walk past each day as a student. Eventually, in another hand, the answer was written: "Yes, but I'm leaving soon." Humanity has plundered millions of years of sunlight stored in oil and gas, cut down forest, shot the passenger pigeons, eaten whales and turned Eden into Pandæmonium. They rightly conclude that "planetary evolution now depends on our behaviour".

How to Build a Habitable Planet is an accurate and enjoyable read. The omission of a detailed biogeography and multiple chemical and mathematical equations doesn't hurt, and makes it accessible to the inquisitive non-scientist prepared to do a little work while reading. Meanwhile, those familiar with the first edition will relish the comprehensive update.

In the Gnomologium Vaticanum, Socrates is asked if the planet is spherical. He doesn't know: he hasn't been far enough away to see. Nowadays, we can both step away to see Earth from afar, and delve into its great depths. Langmuir and Broecker's excellent adventure would have, I'm sure, given him the greatest delight.

\section{REVIEWED BY EUAN G. NISBET}

Euan G. Nisbet is in the Department of Earth

Sciences, Royal Holloway, University of London, Egham, Surrey TW20 OEX, UK.

e-mail:E.Nisbet@rhul.ac.uk 